\title{
El reinado del Cornificio y el exilio de las Musas. El filósofo educado en las Artes en la Antigüedad arcaica y en la Europa medieval hasta el siglo XII
}

\section{The Kingdom of Cornifici and the exil of the Muses. The philosoph educated in Arts in Ancient Age and in Medieval Europe until 12th century}

\author{
Diego Pintado \\ nulliusverba@outlook.com
}

Universidad del Salvador (Buenos Aires)

\begin{abstract}
Resumen: Este estudio describe y analiza el tránsito de un paradigma educativo (antiguo, clásico y medieval) a un nuevo paradigma (el universitario, hacia el siglo XII). Se examina el origen y el desarrollo de un paradigma educativo y de formación que se remonta hasta la Grecia arcaica y que se mantuvo en vigencia en la Europa medieval hasta la creación de las universidades en el siglo XII. La tradición educativa de las artes liberales, conocida también como disciplinae cyclicae, es analizado como heredero directo de la tradición arcaica y pitagórica griega basada en la formación por las Musas. Se examinarán las similitudes y paralelismos entre las Musas y las Artes a la luz de la obra de Marciano Capela, De nuptis Pbilologiae et Mercuri. Luego se estudiará en modo conciso la figura del Cornificio, recreada por Juan de Salisbury en su Metalogicon, y se meditará sobre la relación de esta figura paradigmática y el contexto social, cultural, histórico, político y religioso que acaba dando lugar al nacimiento de los primeros estatutos universitarios.
\end{abstract}

Palabras clave: filología clásica, filosofía medieval, artes liberales, filosofía del arte, universidad medieval

\begin{abstract}
This paper treats the question of how the archaic and classical education paradigm is replaced by a new one based on institutionalization. It concerns about the origin and development of one education paradigm of schools, and the other paradigm, the institutional one, current and prevailing since the creation of the institution of university emerged about 12th century. The Liberal Arts education, also known as disciplinae cyclicae education, is analyzed according to the archaic and pithagoric greek tradition based on education by Muses. We will find similarities between Muses and Liberal Arts according to Martianus Capella's work De nuptis Philologiae et Mercuri. Finally, we will observe this problem in John of Salisbury' work Metalogicon and his central symbolic figure of the Cornificius.
\end{abstract}

Keywords: classical philology, medieval philosophy, liberal arts, university in Middle Age 


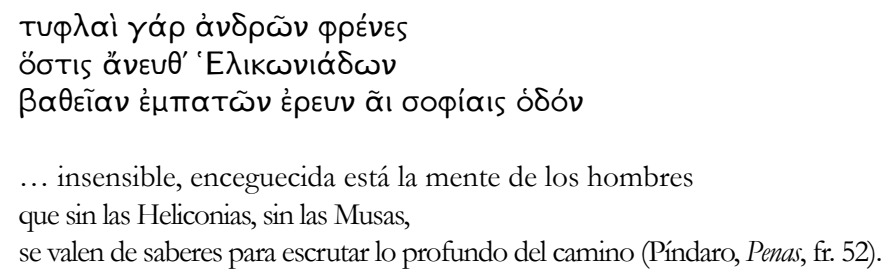

\section{Introducción}

En este trabajo nos ocuparemos de algo que nuestra tradición conoce con la palabra educación. Confesamos, desde ya, la insatisfacción que nos produce este concepto por su vaguedad y sus imprecisiones. Nos interesa aquí la historia de la formación de los espíritus en las artes y en las ciencias en la tradición occidental desde tiempos arcaicos hasta la Modernidad. ¿Dónde se formaban los maestros en las artes del lenguaje, de la filosofía, de la lógica, de las matemáticas, de la música, de la astronomía? ciban a escuelas, a templos, a universidades, a academias? ¿cuáles eran los criterios que determinaban quién era un docto, un versado o un experto, y quién no, y quién tenía autoridad y potestad para enseñar un arte... y quién no? Nos parece que estas preguntas son importantes desde todo punto de vista: filosófico, político, antropológico, religioso, etcétera. Nos obligan a repensar y revisar nuestra realidad presente, y recordar asimismo cómo se desarrollaba lo que hoy conocemos como «educación» en tiempos antiguos.

Este conciso estudio se ocupará de indagar acerca de la relación entre el hombre y las Musas en la educación en tiempos arcaicos; también de la formación en aquellas épocas en las que no existía la universidad, y esto nos obligará a preguntarnos qué es la universidad, y dónde y cómo se estudiaba cuando la universidad no existía.

Entendemos que en la historia de la cultura occidental hay dos grandes etapas en la tradición formacional: la educación móusica, iniciática, personalizada en la trasmisión directa maestrodiscípulo y centralizada en el maestro, y la educación institucional, impersonal, universitaria, que comienza en la Europa medieval hacia el siglo XII. Nos interesa hacer un recorrido, no muy extenso pero imprescindible y necesario, por aquellos tiempos arcaicos, y luego antiguos, y dar cuenta de algunos conceptos e ideas centrales que regían la trasmisión educativa y formadora de las almas humanas, y como después esta tradición formativa pasa a la Europa medieval y florece en ella y prospera, particularmente en tiempos carolingios, dando grandes e inmortales nombres como el de Escoto Erígena o Anselmo de Aosta, Pedro Abelardo o Juan de Salisbury, hasta que finalmente se produce la instauración de la universidad como proceso de institucionalización, con sus claros... y sus oscuros. 
Quizás es momento de repensar cuál es el objetivo último de la formación educativa de un ser humano. Este objetivo último es en nuestros días el título o acreditación: licenciatura, tecnicatura, doctorado, maestría, etcétera. Cabría preguntarnos si esto fue así originariamente, y es muy probable que encontremos que los antiguos diferían profundamente de nuestra concepción actual y vigente: en los orígenes, y durante mucho tiempo, la formación aspiraba a formar hombres sabios, versados en conocimientos, destrezas o artes, iniciados en un saber acumulado, desarrollado y trasmitido. ¿Dónde se halla la diferencia que nos separa de ellos? La diferencia yace en el problema de la acreditación para enseñar o para ejercer el oficio o la enseñanza del oficio. Esta acreditación se la llamó licentia o facultas, es decir, licencia o facultad para enseñar o ejercer. La educación sufrió en algún momento de los siglos XII y XIII un desplazamiento de sus objetivos últimos y fundamentales: se concibió un nuevo sistema de formación educativa concentrado y destinado a resolver el problema de la licencia o acreditación para ejercer y sobre todo para enseñar. Así es como nace el sistema universitario: para dar respuesta a un problema, a saber, el problema de quién ha de estar facultado para ejercer y enseñar y quién no, qué normativas, exigencias, incentivos, condiciones y reglamentaciones deben instaurarse para determinar a quién se le otorga licencia y habilitación para el oficio. Al mismo tiempo, los estamentos políticos y sacerdotales lograron, gracias a la creación de la universidad, tomar el control, en mayor o menor medida, sobre la educación.

Aproximadamente ocho siglos después de la fundación de las primeras universidades y sus estatutos, nos preguntamos si no es hora de reflexionar acerca de cuál es la finalidad última en el proyecto de formación; nos preguntamos, aparte, si el problema de la facultas o licentia para enseñar o para ejercer no ha terminado absorbiendo y apoderándose por completo, en totalidad, del foco, de las miras, del quehacer y de las metas y disposiciones del sistema educativo universitario, y de la educación en general, volviéndose inclusive incapaz de pensar la excelencia, la sublimidad y la perfección sino a través del juicio y veredicto falible, tiránico y tantas veces ciego, injusto y burro de los exámenes y de la curriculocracia.

Orientaremos nuestro itinerario indagando las palabras y los conceptos más importantes y fundamentales en la tradición educativa de Occidente: meditarlos por un momento, volver a pensarlos, hacerlos hablar a la luz de las diferentes épocas: ¿qué era un sabio en tiempos arcaicos? ¿qué eran las Musas para el griego? ¿qué quiso decir Marciano Capela cuando habló de las bodas entre Filología y Mercurio? ¿qué era la filología para los antiguos y para los humanistas? ¿qué son las Artes liberales y por qué se llaman «artes» y por qué «liberales»? ¿qué es el Cornificio, del que nos habla Juan de Salisbury? ¿por qué surgió la universidad? ¿qué diferencia hay entre la universidad y la academia o el liceo? ¿es nuestro sistema de educar y formar superior o deficiente respecto al de los antiguos? ¿en qué hemos progresado, de qué nos hemos olvidado y en qué pudimos habernos extraviado? ¿cuáles son las glorias y cuáles son las miserias de nuestro modelo de formación... que es el único que conocemos? 
Diego Pintado. El reinado del Cornificio y el exilio de las Musas. El filósofo educado en las Artes en la Antigüedad arcaica y en la Europa medieval hasta el siglo XII

\section{E1 sabio originario como artesano}

.. pues debe tener la experiencia del bronce, de la piedra, de la madera, y de allí ascendemos hasta alcanzar la más alta experiencia, la del mundo divino (Disandro 2004: 232).

Formación quiere decir formar la mente y el alma en el arte, entendido arte en sentido amplio y tradicional. Recibir el arte es recibir el oficio, el conocimiento, la técnica, la destreza y la tradición que es revelación y experiencia condensada conforme con el orden inteligible y espiritual. En la formación está implicada la educación de las almas, una nueva forma y estructuración que van a recibir, y no una mera transferencia de conocimientos seleccionados que se han de alojar en una memoria. ¿A qué aspiraba la formación en tiempos arcaicos? A formar sabios, pero... ¿qué era un sabio, originariamente?

Carlos A. Disandro dejó estudios muy valiosos, interesantes, reveladores, de infrecuente belleza y profundidad, como filólogo clásico y como latinista. Ignorado por el establishment académico argentino, y para peor relegado por sus marginadas e imperdonadas posturas políticas e ideológicas, Disandro es sin embargo uno de los estudiosos más notables que ha tenido la Argentina en el área de la filología clásica y de los estudios humanistas. A él quisiéramos acudir para responder a estas inquietudes, ya que eso, y no arqueología erudita, es el oficio y el arte del filólogo: rescatar de la oscuridad y del olvido el sentido y el significado perdido de las palabras, de las sentencias, de los himnos, de las historias, de las letanías, de las epopeyas, de las tragedias, de las ideas, las creaciones del arte, sumergidos bajo capas y capas de ignorancia y superficialidad superpuestas a través de los siglos. El genuino filólogo es una figura divina, o semi-divina, como lo es el auténtico poeta, que, a diferencia de éste, su labor no es la creación sino animar y revivir las creaciones inmortales, ungirlas del don del habla comprensible y de la voz viviente a los oídos, abrir un diáfano umbral de acceso luminoso de la visión a ellas... en suma: infundirles hálito vital.

Del sabio arcaico, dice Disandro:

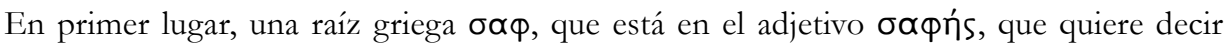
«luminoso, claro, diáfano, transparente». Y una raíz que está en la palabra latina sapiens, en el sentido de gustar, indica un contacto experiencial con la cosa. [...] Desde el punto de vista epistemológico, бoфós querría indicar un estado de claridad interior en el hombre; la lumbre cósmica habita la interioridad del hombre y lo hace diáfano a sí mismo. Pero esta luminosidad está en relación con una experiencia del mundo, con una visión del mundo que se combina en un acto de saber. Por lo tanto бoфós quiere decir «sabio», sabio en el sentido de que alcanza una claridad interior que corresponde en el mundo del hombre a la claridad de la lumbre cósmica y a una aprehensión directa de una realidad que es gustada experiencialmente. 
$[\cdots]$

Retornemos al término бoథ $\mathrm{s}$ en Homero, quien usa el término para indicar una actividad de aquel sujeto capaz de construir una cosa con una cierta perfección, por ejemplo un escudo, una lanza, un casco, un carro es el primer sentido de ooфós. Pero para poder construir esa cosa, sea escudo, lanza, casco, carro, etcétera, se precisa una cierta inserción en el todo, porque esos elementos están simbólica y significativamente unidos a un mundo lingüístico, religioso, político. También en este caso el término homérico nos advertiría sobre esa doble condición: la del artesano. El primer sentido de ooфós sería «artesano», de cuya destreza insertada en un mundo armonioso surge este acto de claridad y de experiencia, pues debe tener la experiencia del bronce, de la piedra, de la madera, y de allí ascendemos hasta alcanzar la más alta experiencia, la del mundo divino (Disandro 2004: 230-231 y 232).

Disandro nos presenta en primer término una etimología que remite a la claridad y a la luminosidad. La sabiduría tendría que ver con lo claro y luminoso, con una visión diáfana e interior de lo real, de la totalidad. Después, nos lleva al mundo arcaico y originario, el mundo de Homero, y nos recuerda que el sentido originario de «sabio» es «artesano». Pero Disandro se preocupa de esclarecer esta palabra: es un concepto distinto al nuestro, ya que no se trata de hacer meramente un casco o carro o escudo, y nada más, sino que «se precisa una cierta inserción en el todo, porque esos elementos están simbólica y significativamente unidos al mundo lingüístico, religioso, político», o sea: el artesano realiza en su labor la obra de arte y fecunda su obra en términos simbólicos y significativos que redimensionan sus creaciones. Hasta un jarrón o vasija lleva ornamentalmente impresa a la totalidad del orden cósmico. El escudo, tal como lo concibe el artesano arcaico, es decir, el sabio, es un ente semántico, simbólico y espiritual, y luego en segunda instancia es un útil para defenderse en un campo de batalla. Su entidad numénica antecede a su utilidad práctica y material. Comprendemos entonces que la creación de un escudo o un jarrón o una espada no puede dejarse en manos de quien solamente sabe serruchar madera o fundir metales o dar forma a la cerámica y cuente incluso con algún sentido estético, eso no alcanza: es indispensable para la creación del artesano que exista «el mismo acto poético que, en la perspectiva ex auditu, proyecta la lumbre de la tradición en la lengua y otorga esa claridad al mundo humano».

Así, nos damos cuenta de la complejidad y de los elementos implicados en la formación del artesano: saberes, técnicas y conocimientos que trascienden a la contemplación rústica y utilitarista de los objetos. Una formación espiritual, e indudablemente iniciática, ante todo, que en un solo término deberíamos llamar religiosa, en un sentido amplio y no eclesial de la palabra. La formación de un albañil tanto como de un arquitecto no podría diferir, en aquellos tiempos arcaicos, de la que recibe un iniciado en la Masonería en los primeros tres grados, llamados grados simbólicos. Un cuerpo de conocimientos trasmitidos que para la mentalidad profana es un mero ornamento más o menos inútil, superficial y secundario del que se puede prescindir tranquilamente en el taller de un artesano. Exponer y recrear como filólogos el escenario espiritual creativo de un artesano arcaico nos permite entender y elucidar todas las áreas, ciencias, técnicas y conocimientos involucrados en la trasmisión iniciática y en la formación de las almas para cualquier creación. 
Entonces, el sabio es aquí el creador, y sus creaciones — desde un escudo o una espada hasta un carro o un jarrón — son obra poiética, son obra de arte; divina, móusicamente inspirada, en la que no se trata de la confección de un «objeto útil» al que se le agregan ornamentos simbólicos, sino que, al revés completamente, se trata de una obra de arte preñada de simbología, inspirada, que luego, recién en segunda instancia, posee además, también, adicionalmente, una utilidad práctica o material. El

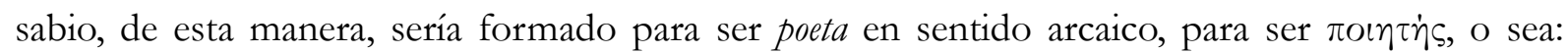
formado para ser creador. Y la formación — lo que hoy llamamos «educación»— estaba enteramente en función de eso, y eso era su fundamento, su razón de ser y su sentido último.

\section{Las Musas y las Artes}

Ellas... sostienen el orden cósmico, el orden humano y el vínculo entre ambas realidades. [...] todo lo existente carecería de sentido si no estuviese coronado por el canto de las Musas (Dissandro 2004: 212; 223).

¿Qué son las Musas... además de divinidades femeninas representantes de las ciencias y de las artes? Las Musas pueden definirse como las Artes mismas, concebidas éstas como divinidades. En términos politeístas, son Diosas. Para nuestra mentalidad esto es chocante y poco comprensible: no entendemos cómo puede ser que el orden cósmico dependa de la danza o de la historia o de la elegancia en el hablar. Los antiguos, tendemos a pensar, era gente supersticiosa y algo infantil. Nos preguntamos, mutatis mutandi, qué pensarían los sabios antiguos de nosotros; seguramente pensarían que una civilización en la que nada se hace según el dictamen y el auspicio de las Musas, y que además de eso les resulta una ingenua y supersticiosa puerilidad creer que la inspiración superior es indispensable y sostiene el orden humano y el orden cósmico, es sin lugar a dudas una civilización de «hombres-vientre»:

\footnotetext{
La revelación de la Musa según el principio teándrico despierta entonces la rememoración del contenido de la memoria divina, que es incambiable, absoluta y perdurable. Rememoración que inhabita la mente del hombre, abierta por las Musas a la posesión de la verdad. [...] Esta revelación distingue en el canto dos categorías de hombres; para Hesíodo la humanidad se escinde según los hombres sean o no hijos del as Musas, según adviertan la rememoración que conduce a ád será el hombre musical (musical en el sentido etimológico de la palabra), construido y abierto según el principio de la rememoración de las hijas de la Memoria divina. A los hombres que

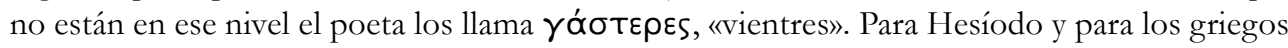
herederos de esa noción, la unión con la revelación de las Musas causa una escisión en la humanidad: los hombres que están instruidos en el canto musical y los que están separados de él, es decir, los «hombres vientres». Los primeros, los hombres musicales, son los que mantienen la continuidad de la humanidad, el vínculo con el principio teándrico; en tanto
} 
que los «vientres», separados de él, están en una suerte de oscuridad sin tener posibilidad de rememoración. Los «hombres vientres» no pueden rememorar la interioridad divina; no están entonces poseídos por la verdad (Disandro 2004: 221-222).

En estas palabras de Disandro creemos encontrar la respuesta que darían los antiguos a nuestros juicios y pareceres que tenemos de ellos, de sus creencias y de su cosmovisión. Las Musas son una dimensión perdida para nuestra civilización, al menos occidental. Para las civilizaciones arcaicas y originarias todo lo que se elabora en un taller no es industria ni artesanía simplemente, sino ante todo arte, pero asimismo nada que sea arte puede estar desprovisto de la inspiración mousical, o sea, inspiración divina.

Disandro, como filólogo inspirado antes que agudo y acertado, descubre que las Musas son formas divinas e hipostáticas de la Memoria divina, y por lo tanto, la inspiración es un despertar: la inspiración mousical del sabio es anamnesis, reminiscencia, en el sentido platónico del concepto.

Escoto Erígena, que es uno de los grandes iniciados en la tradición neoplatónica y en las Artes, y uno de los grandes exponentes cristianos de una civilización, tardíamente desarrollada, en conformidad con las Musas y las disciplinae cyclicae, escribió:

\begin{abstract}
Siquidem a philosophis ueraciter quaesitum repertumque est artes esse aeternas et semper immutabiliter animae adhaerere ita ut non quasi accidentia quaedam ipsius esse uideantur, sed naturales uirtutes actionesque nullo modo ab ea recedentes nec recedere ualentes nec aliunde uenientes sed naturaliter ei insitas, ita ut ambiguum sit utrum ipsae aeternitatem ei praestant quoniam aeternae sunt eique semper adhaereant ut aeterna sit, an ratione subiecti quod est anima artibus aeternitas administratur, ousian enim animae et dynamin et energeian aeternae sunt, an ita sibi inuicem coadhaereant, dum omnes aeternae sint, ut a se invicem segregari non possint.

(Porque los filósofos indagan, realmente, y encuentran que las artes son eternas y adheridas inmutables en el alma, de manera que no parecen ser accidentes de las mismas, sino virtudes y acciones naturales [al alma], que en modo alguno se apartan de ella sino que son inherentes por naturaleza a ella; y así se presenta, sin certeza, el dilema acerca si son las artes las que le proporcionan eternidad a ella [al alma] dado que son eternas y siempre le son inherentes para que pueda ser eterna, o si es en razón de que el alma es la entidad subyacente por lo cual suministra la eternidad a las artes — puesto que la ousía del alma, la dynamis y la energeia son eternas-, o si hay una adherencia mutua, dado que todas son eternas, de tal modo que no pueden mutuamente escindirse.) (Periphyseon, I, 486 D).
\end{abstract}

En esta sentencia de Erígena, deslumbrante por su poder revelador, hallamos algo desconcertante al comienzo, cuando habla de energeia u operatio animae. Esto nos sugiere repensar por un momento qué significan estas palabras para los antiguos. La energeia es aquí traducida por operatio, y en la escolástica se ha traducido también por activitas. Se trata de un estado, mas: ¿cuál es ese estado... un estado de qué? El hallarse en el estado del estar-haciendo, estar trabajando, estar en funciones, estar en actividad. Son conceptos muy profundos y difíciles de describir incluso para los antiguos. Debemos pensar que hay una dimensión en las cosas, y en el alma, que es la dimensión de la actividad, un estar-haciendo o un estar-actuando en la existencia. Dicho estado compromete la 
esencia misma del alma, o de las cosas. Podemos hacer muchas cosas, o incluso «hacer nada», o abandonarnos a un hacer deficiente, extraviado o indolente, o sinsentido. La premisa parece ser que el alma siempre está actuando, y no que a veces actúa y otras descansa; y que asimismo hay por encima del «acto específico», un actuar general, un rumbo u orientación general del estar-actuando. La palabra «actividad» tiene el problema de que pensemos en una actividad que realizamos semanalmente: ir a patinar, ir a clases de pintura, o ir a trabajar... etc. Aquí se trata de una actividad como condición ontológica: el alma es actividad también. El dilema que se plantea sería entonces en estos términos: ¿cuál es la activitas propia, esencial y natural al alma... y cuál no? ¿qué modo de conducir el tiempo, el actuar y la existencia está en conformidad con la naturaleza de nuestro ser, de nuestra alma, y qué modo se aleja de ello y nos desvía o nos estanca o nos empobrece y nos hace descender, decaer, errar o perdernos de nuestra propia esencia? La religión, cuando es religiosa, responderá que la actividad natural al alma es la religiosidad en todos los órdenes y dimensiones de la existencia humana. Pero un filósofo platónico, que también es religioso como lo era Platón, responderá de una manera diferente, y así lo hicieron Boecio, Capela o Erígena: la actividad propia, natural y esencial al alma humana es actuar, es decir, estar, es decir, ser y existir activamente, conforme a los principios divinos, ya no de un Dios abstracto mediado por mandamientos y preceptos de un texto sagrado, sino por la Memoria divina mediada por las Musas, o sea, por las Artes: estas Divinidades pueden regir, inspirar, subordinar y dirigir todos los actos de nuestras vidas, como almas, como personas y como civilización, de acuerdo con ese orden oculto, que no es otro que la esencia última de nuestro propio ser. Por las Musas, todo es inspirado divinamente y elevado valiéndose de la sacralidad: la creación de un escudo o de un carro o de un jarrón, impregnados de espíritu en sus signos religiosos; la erección de una casa, de un edificio, de una torre, de un templo en su disposición propia de una astronomía y una geometría sagrada; la composición musical, dramática o literaria, según las técnicas móusicas y los mitos divinos; los juegos y las fiestas en la representación simbólica, e incluso la embriaguez o la prostitución asumiendo la recreación de un ministerio iniciático; hasta finalmente la elaboración artesanal de nuestras ropas y prendas, embebidas de colores y figuras y formas que obedecen a la sacralidad de una simbología perenne, en donde sacrum ha de pensarse «como esfera o franja sustraída, que concentra la densidad numinosa del ente» (Disandro 1995: 143).

En esa sentencia de Escoto encontramos, por otra parte, descripción casi perfecta, y hermosa por lo demás, de la relación entre las Musas y el alma del sabio, que en este caso no es el artista ni el artesano sino el filósofo. Esto quiere decir que los principios de las artes y de las ciencias móusicas, las ciencias y las artes arquetípicas y divinamente inspiradas, son perennes, nadie los inventa sino que se descubren por reminiscencia: preexistían en el alma. Y no solamente eso: lo más importante que ha de saberse es que ninguna creación humana tiene en principio una finalidad burdamente práctica, nada; ni siquiera un jarrón o un martillo, es una «producción», tal como bárbara y groseramente pensarían los antiguos - lo comprende el sentir propio de nuestra sociedad industrial y tecnocrática, de la que no se sustrae tampoco el artista o el estudioso de las artes que no concibe otra finalidad para las obras artísticas más que para exhibirse en una exposición o para darles lugar en un museo. El significado subyacente es que todo está precedido por la intención anamnésica de recordarnos 
un orden propio y superior en todas las cosas, y un lugar único que poseen todos los entes en la arquitectura semántica de lo real —y esa arquitectura es estructurada por el ojo divino que habita en el alma, que no es otro que el orden de la memoria y el ojo de la reminiscencia.

\section{Las bodas de Filología y Mercurio}

Marciano Capela es autor de una obra extraña pero trascendental en importancia en la historia de la civilización occidental, cuyo título es Las bodas de Filología y Mercurio. En esta obra, no fortuitamente escrita en verso y en prosa, como La consolación de la Filosofía de Boecio, Capela presenta a las Artes liberales, con la singularidad de que la elegida y coronada, por encima de las siete artes, no es la Sabiduría ni la Filosofía, sino la Filología. Ante todo, téngase en consideración que Mercurio representaría, explicándolo rápidamente y en rasgos generales, a la comunicación y relación entre lo divino y lo humano, entre lo superior y lo inferior, entre le Cielo y la Tierra, y a su vez, la comunicación y relación entre los hombres y entre todas las cosas. Mercurio por lo tanto tiene bajo su dominio a la civilización, a la escritura, a los oficios, a las técnicas, a los conocimientos, a la economía, al comercio, al intercambio, a las traducciones e interpretaciones y... al lenguaje.

La tradición, o la ocasión histórica propiciada por los Dioses — aquí de ninguna manera estamos en contexto cristiano- - parece haber visto óptimo y acertado celebrar bodas entre Mercurio y la Filología... y no con la Sabiduría. El dilema, en un comienzo, es con quién ha de unirse Mercurio; entre las candidatas figuran Sabiduría, Mántica e incluso Alma. La Sabiduría es irresistible en su radiante preciosura, pero célibe: solitaria, exclusiva, luminosa y saturnina a la vez, habitante de los desiertos o de las altas cumbres; unirse con Mántica contraería el peligro de que, en todos los órdenes de lo real, todo acabe fundado sobre artes mágicas, destrezas ocultas matemáticas (numerológicas, astrológicas) ${ }^{1}$ pero asimismo la inevitable degeneración en superstición; casarse con Alma resultaría en un dualismo espiritualista que dejaría sin luz ni redención ni elevación a todo lo corpóreo, a las formas materiales, pero también abandonaría a los mundos imaginarios y a las creaciones artísticas que caerían bajo el excluido y despreciado, insalvable e irredimible hemisferio de lo mundano, que es lo corruptible, que es lo perecedero. Finalmente, la resolución es por las bodas con la Filología; la pregunta es por qué.

1 Nos parece oportuno relacionar el simbolismo de una hipotética unión nupcial entre Mercurio y Mántica con la tendencia, siempre latente desde tiempos de Capela hasta Bruno, de que predomine una cosmovisión matemáticomántica en desmedro de otras como la perspectiva filosófica o filológica o teológica, ya que no debemos olvidar que «La séptima de las artes mecánicas es el 'arte adivinatorio'. Los filósofos del siglo XIII coincidían en subdividirla en cinco partes: la mántica, la matemática o mathèsis, el arte de los sortilegios, el arte de las ilusiones, el arte de los conjuros y el arte de los maleficios. Se contaban cinco tipos de mánticas: la piromancia, la hidromancia, la aeromancia, la geomancia y la necromancia. La enumeración de esas técnicas de adivinación era un lugar común literario cuya mayor parte de elementos eran conocidos desde el siglo XII, puesto que figuran en detalle en el Didascalion de Hugo de San Victor» (Liberá 2000: 182). 
Si pensamos a Mercurio como la civilización, la cultura, la comunicación, el lenguaje y las relaciones entre seres humanos, entonces no es para nada bueno que Mercurio esté solo, o que éste en mala compañía. Mercurio debe estar unido a un espíritu ético, a alguna inteligencia superior, a alguna forma de sabiduría, por lo menos. La soledad de Mercurio llevaría a una tecnocracia mercuriana, o tal vez a una plutocracia tecnológica y delictiva superdesarrollada. Mercurio podría, asimismo, no casarse y convertirse en ángel del Dios monoteísta; ésta es una posibilidad que no estuvo entre los antiguos griegos y romanos platónicos y neoplatónicos, testigos del ocaso del Imperio, y que advirtieron que la diáfana y preciosa luminosidad de Apolo se inclinaba por las nupcias de Mercurio con la virgen Filología. Una sabia manera de salvar a Mercurio de su peligroso aislamiento y soltería es fusionarse con las Musas, y que su energeia, su operatio, sea mousical; que actúe y obre y conciba y engendre mousicalmente, por inspiración de las Diosas que ahora pasan a ser Artes y son siete.

Pero aún no hemos respondido a la pregunta: ¿por qué entonces no se consumaron bodas poligámicas entre Mercurio y las Musas, y en vez de eso se unió Mercurio con Filología? A eso no nos queda más que responder que obedece a una cosmovisión logoscéntrica, una contemplación de la realidad como centrada en la palabra, en la razón, con eje y cuerpo en el intelecto y en el lenguaje, y así, la filología es indagación y elucidación semántica de todas las cosas. El orden oculto de lo real es un descubrimiento filológico: lo es porque es un descubrimiento semántico, cuando la meditación etimológica de las cosas, los nombres y las palabras, y ejercicio lógico y racional, son lo mismo, y son reminiscencia y estructuración divina e inspirada de lo real. Porque los secretos del ser se descubren en los secretos de las palabras; porque, como afirmaba Heidegger, la palabra es la morada del ser: si la palabra es la morada del ser, si el lenguaje es el depositario de lo real, la Filología se convierte en Musa suprema (la décima Musa, o Musa-Madre), en Arte de las artes (la octava Arte, o Arte-Madre).

¿Qué nos dice Febo, según palabras de Marciano Capela, sobre Filología?

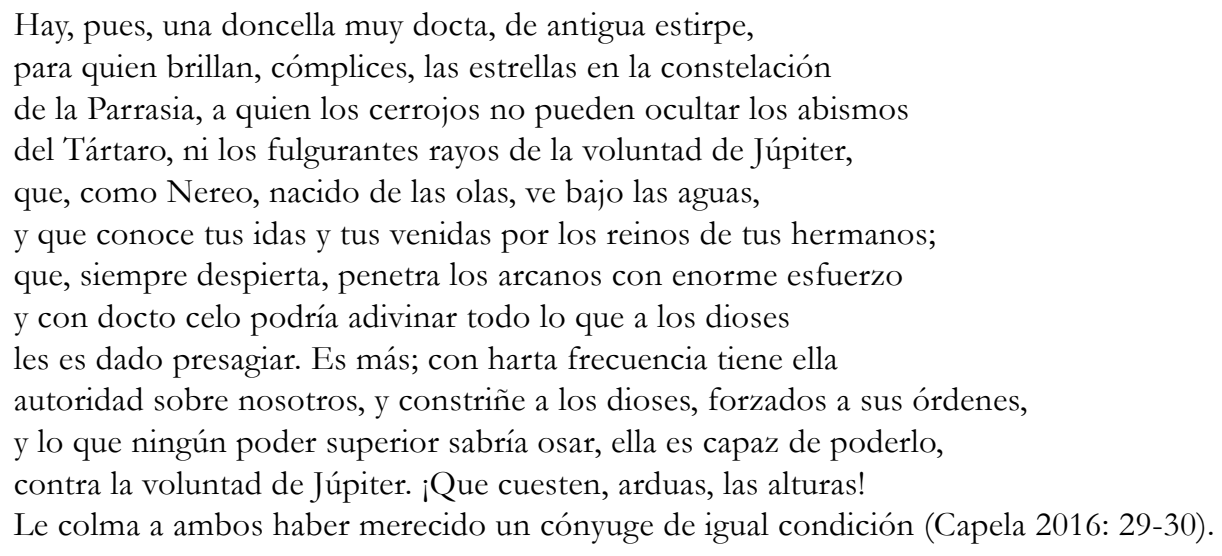

Estos secretos deben contemplarse bajo la consideración de que la palabra es la morada del ser; la consideración de que la estructura semántica es lo mismo que estructura lógica y que esta estructura 
es idéntica a la estructura de lo real. Pero quisiéramos llamar la atención, entorno a Filología, sobre otra cosa más. Acerca de este pasaje, Danuta Shanzer habló de una inequívoca concepción teúrgica, quien afirma que «las aretai de Filología son teúrgicas»:

\footnotetext{
Hay todavía un lado más oscuro del paganismo que se refleja en De Nuptiis: teúrgia y magia. Marciano parece conocer material egipcio, textos similares a los papiros mágicos, asimismo los Lithica pseudo-órficos y los Oracula Chaldaica. Varios fragmentos de los Oracula son los que pueden extraerse del texto De Nuptiis, y hay un número de pasajes que con seguridad pueden calificarse como «caldeizantes», y así quizás no sorprenda a nadie que a Filología la describa como un teúrgo (Shanzer 1986: 22).
}

El aspecto teúrgico de la Filología evocada por Capela en estos versos que acabamos de transcribir, lo observamos particularmente en estos versos recién citados, sobre todo los versos finales, en los que Júpiter y el Cielo es coaccionado, constreñido y hasta superado (... in nos ius habet illa, deos urgens in iussa coactos; et quod nulla Quetta superum templare potestas, invito scit posse Iove).

Tener poder coactivo, regencia y potestad sobre lo divino es teúrgia. Y eso es lo que se desprende de los versos citados, que acredita el énfasis de la tesis de Shanzer. O sea: las Artes adquieren dimensión teúrgica, y a partir del momento en el que es instaurada la formación de las almas conforme con el orden de Filología y las disciplinas cíclicas, el artista, es decir, el iniciado en el ciclo de formación en las siete Artes, estará haciendo descender cualidades y esferas divinas en la técnica y aplicación geométrica, retórica, astronómica, arquitectónica, musical o numérica de su arte, y de la obra —en la misma medida en que se eleva a la esfera de lo divino cada objeto, función, elemento, tarea, palabra o material.

\section{Artes liberales y el monje medieval como Movoı́ós àvńp}

Un gran dilema entre los historiadores es establecer acertadamente en qué momento la Antigüedad da paso a lo que los historiadores modernos han preferido llamar «Edad Media». Los abusos e imprecisiones terminológicas son muchos y reiterados, pero nos vamos abstener, en esta oportunidad, de todo intento de elucidar vocablos y conceptos involucrados en este campo particular de estudios históricos y culturales. Diremos que la civilización grecorromana no tiene su ocaso con la caída de Roma, y que pervive, con algún esplendor, durante algunos siglos. Los más grandiosos tesoros del conocimiento, de las artes y de la filosofía, sobreviven no solamente en monasterios, sino en diferentes órdenes de la vida «medieval»: desde las liturgias hasta los principios de la arquitectura, desde la música hasta la jurisprudencia. Nadie objetará que hubo una dramática transformación: sólo nos limitamos a decir que existió, durante mucho tiempo, una continuidad en diversos órdenes, como por ejemplo, en el de la formación educativa. 
La formación educativa que persiste hasta aproximadamente el siglo XII es la continuidad de la tradición formativa de la Antigüedad tardía, desarrollada en gran medida con la impronta del neoplatonismo. No es una tradición cristiana, y desde luego tampoco semítica. No sería del todo exagerado hablar de una continuidad, en el ámbito formativo y educativo, donde sin embargo ya no se profesa la religión de los griegos y los romanos sino la nueva religión; todo lo restante - las ciencias y el conocimiento, la filosofía y los poetas, la música y la ingeniería, las artes y la jurisprudencia - permanece como una continuidad: sigue siendo griego y sigue siendo romano.
(...) las nueve Musas son la intermediación forzosa entre el mundo absolutamente divino y la concordia del mundo cósmico-humano. Tal es el sentido del a presencia de sus nombres, que provenientes de la tradición griega, no son rechazados por la tradición medieval cristiana. Tan es

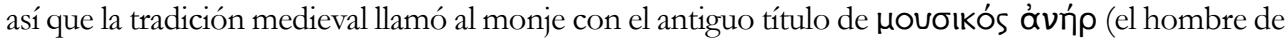 las Musas). En el monje medieval se reproduce, en alguna medida y con caracteres propios, aquella

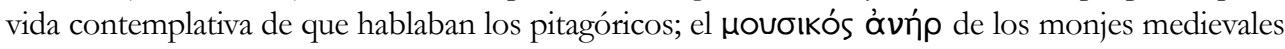 es una resonancia del ideal pitagórico de la armonía cósmico-humana. Salvo que en la época de Pitágoras no existía históricamente la Iglesia, aunque sí existía en su realidad intradivina. No estoy haciendo una equiparación, sino mostrando una correspondencia.
Podríamos decir que Pitágoras tuvo una preciencia de la Iglesia, en tanto que cuando el monje practicó la vida del Movoıkós ơvińp, la Iglesia estaba históricamente manifestada. La relación entre el pitagorismo y el monacato medieval es pues muy profunda (Disandro 2004: 212-213).

Disandro ama como filólogo clásico y como filósofo católico a la tradición griega y romana y a las glorias de una civilización auspiciada por la Iglesia. Sin embargo, no estamos seguros hasta qué punto la Iglesia se sintió cómoda y feliz entre las Musas y las Artes liberales. Puede presumirse, con toda lógica y sensatez, que la Iglesia pudo haber experimentado celos —y los miedos que siempre escoltan a los celos-; la Iglesia debió en algún momento contemplar a las Musas como hermosas, excelsas y cautivadoras nodrizas formadoras de las almas humanas y esto debió haberla inquietado y preocupado bastante. Esta relación de las almas humanas con potestades divinas, es decir, con Diosas de la antigua religión, tenía algo de inquietante sin dudas, algo nada tranquilizador, para la Iglesia y para su doctrina. Toda esa perfecta armoniosidad que - no sin algo de ingenuidad - describe Disandro, podía estar incubando un espíritu renacentista que anticipara la descristianización de un retorno total, radical, drástico y excluyente a las fuentes grecorromanas. O sea: lo que un cristiano llamaría un «renacimiento paganizante». Por aquí ya podemos empezar a vislumbrar la preocupación y la necesidad de la Iglesia de una reforma o sustitución de esta tradición formativa-educativa vigente — reforma o sustitución que finalmente será consumada con la instauración de la universidad.

Debemos preguntarnos, nuevamente, qué son las artes en este período: qué entienden estos hombres por arte, qué se comprendía por que aquella época con esta palabra. El significado de estos conceptos, tanto el de arte como el de artes liberales, debe rastrearse en la tradición griega y romana, en la formación iniciática originaria revivida y actualizada en los últimos siglos de la Antigüedad, contemporáneos al ocaso del Imperio Romano. Las Artes liberales son para Filología lo que para Filosofía o Sofía fueron las Musas, y este concepto de arte nada tiene que ver con la mera técnica ni con un compendio de conocimientos metafísicos: cada una de las Artes, como cada una de las 
Musas, es irreductible en su dimensión, como cada una de las esferas divinas es irreductible, como cada una de las partes corporales y espirituales del ser humano son irreductibles sin eliminar con ello al ser humano, y como cada uno de los elementos constitutivos del cosmos es irreductible a uno solo sin reducir con ello al cosmos al caos o a la nada. Cada una de las Musas tiene una tarea, como la mano o el ojo tienen una tarea y son en su tarea y en su función irreductibles; cada Musa tiene su érgon y en su areté, desde el momento que estamos constituidos de Cielo y Tierra, de cuatro elementos, de tiempo y espacio, de colores y tonos y sonidos, de luz y de sombra y de matiz, de lo masculino y lo femenino, de mineral, vegetal y animal, de palabras y de ideas, de ojos y manos, de oídos y lengua y nariz para oler.

Si este es el significado y el sentido que conservan las artes en los monasterios medievales durante algunos siglos, convendría más bien, para ser más exactos, hablar directamente de una traslatio studiorum: centros de estudios, de ordenación, de formación y de conservación de artes y conocimientos, que debido a los cambios y convulsiones históricas y políticas se van desplazando de una ciudad a otra ciudad, de una región a otra, a través del tiempo. Estos centros consiguen sobrevivir bajo la forma de monasterios cristianos y la pregunta que nos parece estar autorizados para hacernos es ésta: ¿se trató de monasterios cristianos que acudían al saber antiguo, o en muchos casos — no en todos- se trató más bien de centros iniciáticos pitagóricos, platónicos y neoplatónicos camuflados bajo el aspecto más o menos formal de piadoso monasticismo? Es difícil desechar esta hipótesis si estudiamos la obra de un hombre como Escoto Erígena, su Periphyseon y sus Annotationes in Marcianum. ¿Está más cerca de la Biblia y el Evangelio o se encuentra más próximo a Platón, a Marciano Capela y a Boecio?

Erígena es uno de los baluartes de esta tradición que florece y se desarrolla en Irlanda. Lo que se produce en Irlanda debe calificarse, sin más vueltas ni titubeos — mal que le pese a los franceses, a los ingleses y a la propia Iglesia-, como un perfecto caso de traslatio studiorum: allí se constituye un centro de ordenación en los más altos conocimientos dialécticos, lógicos, filosóficos, científicos, lingüísticos, históricos, matemáticos, y a partir de allí se expande el cristianismo por el Norte más boreal y occidental y se consolida, e inclusive se traslada luego a la inculta y rústica Francia de aquel entonces para iniciar en esta tradición a la corte de Carlomagno, la misma tradición que por otras vías florecerá en la España visigoda como lo atestigua la obra de Isidoro de Sevilla. Todo este período histórico de la cultura occidental es el más relegado y olvidado; subsiste brumosamente en el imaginario académico, excepto para unos pocos especializados en el área.

\section{El divorcio de Filología y Mercurio: el exilio de las Musas}

\footnotetext{
... se repliegan, por así decir, las Musas, y el mundo se insume en la oscuridad. Tal es la situación de nuestra época: es la Edad Oscura, en que no tenemos convivencia con los dioses ni tenemos la perspectiva teológica (Disandro 2004: 218).
} 
Hemos dicho que arte no es técnica, meramente, pero que tampoco es un conjunto de saberes aplicables o útiles al acceso de un conocimiento. En algún momento del siglo XII y XIII las cosas empiezan a cambiar, y comienza a concebirse al arte como collectio multorum praeceptorum ad unum finem («compendio de muchos principios tendientes a un fin», como dice Juan de Dacia) o como ordinatio et constitutio cognoscendi finem, cuius homo uult habere cognitionem («ordenación y constitución del conocer dispuesto hacia el fin del que el hombre quiere tener conocimiento», como pensaba Ramón Llull), como transcribe y explica José Higuera Rubio en un artículo:

\begin{abstract}
Estos elementos están ausentes de la definición de ars que Jacques Le Goff ofrece en su conocida introducción a la vida académica medieval (Le Goff, 1956, p. 60). Dicha definición transmitió una ambigua sinonimia entre ars y técnica, lo que ocultó el componente epistémico. La referencia al «conjunto (collectio) de principios dispuesto hacia un fin» que no aparece en la definición aristotélica que Le Goff cita unas líneas después. Sin embargo, en los textos que circulaban por el studium medieval éste era un componente fundamental del ars. La definición citada antes dejó de lado los múltiples sentidos de la definición de las artes en relación a las ciencias y al pensamiento filosófico, lo que sin duda aisló la recepción que el mismo Llull hace del término ars y las connotaciones que tuvo en su época (Higuera Rubio 2013: 71-79).
\end{abstract}

Rubio hace notar algo que los estudiosos modernos — deplorablemente, a nuestro criterio— suelen perder de vista, y es que el arte es tradicionalmente mucho más que técnica, y que es algo más próximo a la poíesis que la tejné. Pero esta explicación de lo que es el arte, si bien rescata al concepto de quedar limitado a nada más que técnica o saber técnico, y le restituye su dimensión «epistémica», como dice Rubio, no obstante todo nos parece insuficiente, por lo menos en el contexto de las Artes liberales. Esta visión del arte, la de Juan de Dacia y la de Ramón Llull, por ejemplo, parecen estar intelectualizando un poco el concepto de ars y restringiéndolo, despojándolo de su sentido originario, y lo más grave: puede entreverse una separación entre las Musas y el arte, al postular un «Arte» solitario, abstracto, tal vez metafísico, acaso monoteísta, pero alejado cada vez más de las artes. El surgimiento de este nuevo «Arte» y su entronización es paralelo a un proceso por el que las artes son arrojadas a un estrato de inferioridad; ese nuevo «Arte», que no está del todo claro cuál es pero que seguramente se trate de la metafísica, es decir, de la teología, despoja a las Artes de su divinidad: de Diosas pasan a ser modestas y empobrecidas sirvientas de la Teología, que ocasionalmente puede presentarse camuflada con el rótulo de «Arte de las artes». Estas Divinidades desposeídas y desamortizadas en su riqueza y potencial y potestades, inician un camino largo y penoso de degradación hasta llegar a nuestros días, en el que «arte» — cuando no es ya cualquier cosa - es pintura y escultura, y el resto de las hermanas, menos afortunadas, habiendo olvidado por completo lo que son, terminaron empleadas como trabajadoras de servicio en la más tosca, insensible y grosera tecnocracia estatal o productivista. Pero debe quedar claro que, a diferencia de las tesis pregonadas por hombres como René Guénon, que adjudican todos estos males al mundo moderno, este proceso degradatorio tiene lugar en el seno de la Cristiandad y es promovido en amplia medida por la misma Iglesia. 
La cultura de las Artes entra en crisis; una crisis que se hace notar particularmente en Francia, y que obedece principalmente a dos razones: a) un incontrolable crecimiento y expansión de estas escuelas de formación en las Artes, que comenzó ya en tiempos carolingios con esa verdadera traslatio studiorum proveniente de Irlanda con Escoto Erígena, y b) el poder y la influencia social, política, cultural y religiosa que adquiere esta suerte de «élite abierta» de maestros y discípulos, que permite una movilidad social vertiginosa a la vez que inquietante para los estamentos tradicionales de poder, en especial para el poder eclesiástico, que ven invadidos las cortes y todos los ámbitos de importancia por hombres formados en el Trivium y en el Quadrivium.

\begin{abstract}
Hacia mediados del siglo XII, se hablaba de París a menudo como de un paraíso, especialmente para aquellos querían iniciarse en el aprendizaje. El salto de la ciudad hacia la preeminencia educativa no pasó inadvertida para los observadores contemporáneos. Guillermo el Bretón, capellán del rey Felipe Augusto (1180-1223), veía una razón evidente por la cual París debió convertirse en un centro de educación tan grande. En la introducción de su crónica hacia el año 1210, Guillermo elogia los atractivos de la ciudad y destaca el rol benéfico del patronazgo real. «En aquella época», escribe, «el estudio de las letras floreció en París. Nunca antes en el mundo, en ninguna época ni en Atenas ni en Egipto, había habido tantos escolares. La razón de esto no es solamente la belleza admirable de la ciudad y su opulencia, sino también la libertad y los privilegios especiales que el rey Felipe y su padre antes que él otorgaron a los escolares» (Ferruolo 1985: 12).
\end{abstract}

En este párrafo del libro de Ferruolo, corroboramos lo que ya está confirmado por el caso de Escoto Erígena: este esplendor es patrocinado por los reyes — no es solventado por la matrícula ni por el mecenazgo de filántropos adinerados ni por entidades religiosas. ¿Y entonces qué estamento de poder puede estar inquieto por la difusión de las escuelas, solventadas con el patronazgo del rey, donde jóvenes - y a veces no tan jóvenes, hay muchos casos como el de Anselmo que comenzaron a estudiar tardíamente- de toda Europa venían a París y otras ciudades a estudiar Artes liberales? La respuesta es: esa institución, celosa y con razones preocupada, era la Iglesia. De lo que se desprende que el único estamento interesado en terminar con este modelo de formación e impulsar la institucionalización, a saber, el modelo de las universidades, era la Iglesia y no «los estamentos de poder» indistintamente. La pregunta que cabe hacerse, y que en esta oportunidad no podremos desarrollarla, es si acaso la contienda entre un paradigma de formación (las escuelas en artes liberales y disciplinae cyclicae) y el otro (la universidad) no son el reflejo, en el campo educativo y formativo, de esa antigua y perenne contienda entre el poder temporal — la monarquía, en este caso- y la autoridad espiritual —esta vez, la Iglesia católica de Roma.

Como quiera que sea, los defensores de una reforma parecen alarmados ante un estado de situación en el que cualquiera pueda obtener con relativa facilidad una habilitación para ejercer enseñanza o para desempeñarse como profesional, por ejemplo como médico. Éste se presenta como uno de los argumentos más fuertes para impulsar la institucionalización de la formación y de la enseñanza. Pero también había otros: 
Curiosidad, ambición, mundanidad —esto era lo que él [Bernardo] veía como los peligros más serios que irradiaban las escuelas, no la dialéctica o las disputas. Con su característica elocuencia y exageración, Bernardo despotricó contra los vicios de los escolares, exhortándolos a huir de la malvada ciudad a refugiarse a salvo en los claustros monásticos (Ferruolo 1985: 47).

Paralelamente, empiezan a proliferar detractores, a veces inclusive satíricos, de las escuelas de las Artes, y la aparición creciente de subversivos culturales que agravan y profundizan la crisis, es decir, personajes públicos que se dedican a criticar y defenestrar a las artes cyclicae, una por una, ponderando una confusa propuesta que oscila entre una especie de escepticismo estético y un reduccionismo cínico, grosero y utilitarista. Por distintos flancos, la tradición formativa escolar empieza a ser atacada y desprestigiada. No sabemos si no faltó, inclusive, quien haya alentado la aparición de estafadores ejerciendo su oficio para precipitar el descontrol y con ello propiciar las condiciones para generar la necesidad de que la función educativa fuera intervenida por los estamentos políticos y eclesiásticos lo más pronto posible.

\begin{abstract}
El hecho de que monjes y escolares estuvieran compitiendo por muchas de esas mismas posiciones y rangos en la Iglesia, es lo que explica parcialmente la oposición de los monjes hacia las escuelas. Pero grandes pensadores monásticos como Bernardo de Clairvaux con certeza sabían que había una cuestión problemática todavía mayor. La expansión de las escuelas y el avance de los escolares supuso cambios considerables en el orden religioso e intelectual, un ámbito que estuvo por mucho bajo dominio de monjes y monasterios. Así, con todos los medios a su disposición, estos líderes monásticos debieron retroceder, o al menos reconsiderar la influencia creciente de las escuelas. En retrospectiva, parecería que los monjes estaban luchando por una batalla perdida contra el avance inevitable de la enseñanza (against the inevitable advance of learning). Pero para los escolares de la época la situación debió presentarse como más peligrosa, especialmente cuando el mismo Bernardo estaba vigilando sus actividades. Mientras los monjes permanecieron hostiles a las escuelas, un serio obstáculo se había interpuesto en el camino de los escolares buscando avanzar tanto en la enseñanza como en sus carreras (Ferruolo 1985: 48).
\end{abstract}

Ferruolo hace notar que lo más peligroso no era tanto la existencia misma de las escuelas y su expansión, sino la influencia que inevitablemente terminaban produciendo en el interior de los monasterios, sobre todo en plano intelectual y teológico. Como complemento, Tamayo y Samorán, en un estudio apologético del sistema universitario y denigrador llanamente del anterior, y anticipando esta gran embestida contra la formación en las escuelas, escribe:

El nivel de las escuelas era, en su conjunto, mediocre; muchas de ellas impartían sólo una enseñanza elemental (leer, escribir, contar); se limitaban a preparar a los jóvenes clérigos para realizar sus tareas litúrgicas. Sólo algunas escuelas podían en realidad considerarse centros de enseñanza superior. Éstos, sin embargo, eran pocos y no siempre estables. Su fama, con mucha frecuencia, estaba ligada con la presencia de un maestro célebre; cuando éste partía, la escuela declinaba. (como fue el caso de la escuela de Lyon con Anselmo [c1050-1117]). Por otro lado, muchos obispos no ponían celo excesivo en promover la escuela de su iglesia catedral (Tamayo y Salmorán 1987: 14). 
No nos ocuparemos de hacer notar algo obvio, manifiesto: que es rotunda y perversa falsedad reducir las artes liberales a «enseñanza elemental» de «leer, escribir, conta»»; nos limitaremos, en cambio, destacar justamente que, eso que el autor observa como una falencia, era en verdad la virtud y el eje de ese paradigma de formación: su carácter era «maestrocéntrico», si la expresión se nos permite; era un sistema que funcionaba basado en la autoridad y en el prestigio del maestro, conformado por él y entorno a él, y que dejaba de funcionar y «la escuela declinaba» si el maestro era un inepto o un mediocre o si se volvía loco o negligente. Ahora bien, lo importante aquí es analizar y juzgar global e intrínsecamente a esta tradición educativa, y no juzgarla por cuestiones de formales o de método por el que funcionaba: mientras uno, el nuestro, depende del buen funcionamiento de la institución, el sistema anterior - atacado por este autor de una manera injusta, maliciosa, pero sobre todo irracional e infundada - dependía, para funcionar bien, de la excelencia del maestro. Y este sistema, centrado en el maestro - y no en la institución — como fuente de prestigio y autoridad y como eje de toda la educación, fue el que dio a la Europa de aquellos tiempos, y a la posteridad, hombres como Escoto Erígena, Isidoro de Sevilla, Anselmo, Juan de Salisbury, Pedro Abelardo, etcétera, los cuales dejan en evidencia que las consideraciones de este autor están gravemente erradas y alejadas totalmente de la realidad.

El proyecto iba a ser la intervención mediante la institucionalización de la enseñanza, estableciendo rígidos estatutos que debían ser aprobados por las autoridades. Las Musas pasarán a un deshonroso plano de inferioridad, relegadas para dar paso a una única «Arte» — como así se presentaría—, que muy probablemente no será sino de una forma encubierta y disfrazada de la Teología, la soberana, que reducirá a la servidumbre a la mismísima Filosofía y que, a lo largo del tiempo, convertirá a las Artes, profanadas ya —esterilizadas, desposeídas de potestades divinas, despojadas para siempre de poderes creadores—, en nada más que «instrumentos» $\mathrm{y}$ «técnicas». ${ }^{2}$

\title{
7. El Cornificio y el nacimiento de la universidad
}

\author{
Nihil sordidum putant, nihil stultum... \\ (Nada consideran horrendo, nada consideran absurdo...) \\ (Juan de Salisbury, Metalogicon, I, 4)
}

\begin{abstract}
2 Puede apreciarse un panorama más amplio, más completo y más revelador cuando penetramos un poco en el contexto histórico de los primeros estatutos universitarios: «Los estatutos de 1215 no fueron reglas sistemáticas impuestas a la universidad por una autoridad externa. El emisario papal que los promulgó no era ajeno a las escuelas de París, ni estaba desfamiliarizado con los asuntos e intereses de la naciente corporación de maestros. Previo a convertirse en cardenal en 1212, Roberto de Courson había sido por doce años o más un maestro eminente de las escuelas y un miembro altamente influyente en la facultad de teología. Si bien carecemos de evidencia concluyente, difícilmente haya lugar a dudas, considerando su preeminencia profesional y su frecuente servicio como juez-delegado papal, que el maestro Roberto había jugado un rol más importante en los primeros episodios de la historia de la corporación universitaria. Su nombramiento como cardenal y sus deberes como emisario papal a Francia (desde abril de 1213) lo removieron físicamente de París, pero no rompió sus sólidos lazos con la corporación de maestros que él había ayudado a formar. Cuando, hacia los últimos meses de su misión como delegado, el cardenal regresó a París con un mandato especial de Inocencio III para 'reformar las escuelas y procurar su futura tranquilidad', él estaba preparado para trabajar con sus anteriores colegas para asegurar sus logros corporativos previamente alcanzados, y completar el programa de reforma interna y regulación que ellos habían comenzado ya durante los años en que él era maestro» (Ferruolo 1985: 301).
\end{abstract}

SCRIPTA, Revista internacional de literatura i cultura medieval i moderna, núm. 8 / desembre 2016 / pp. 1-24 ISSN: 2340-4841 · doi:10.7203/SCRIPTA.8.9281 
La universidad emerge como solución a esta crisis, que de una manera muy concisa y apretada hemos estado describiendo sobre todo en la sección anterior. El crecimiento de las ciudades va acompañado de la expansión de las escuelas, que como hemos dicho contaban con el patronazgo de los reyes. Creemos que la Iglesia fue la principal promotora de una reforma, o sea, de la instauración de la universidad, para dar solución a una crisis, que, como muchas veces ocurre en otros órdenes de la vida social y política, aún en nuestro mundo contemporáneo, nunca se termina por saber muy bien en qué consiste tal «crisis» ni si así cabe llamarla ni qué la originó. Aquí, la «crisis» debe entenderse como una situación de malestar en los estamentos eclesiásticos, en la autoridad religiosa, y su promovida sustitución de un sistema de formación educativa por otro debió explotar estratégicamente los puntos más débiles del sistema que buscaba sustituir: fundamentalmente la «crisis de las licencias» para ejercer o para enseñar; por esa dirección iba su estrategia política más fuerte para motivar la reforma, y es ahí mismo, también, en donde se fundamenta y se justifica hoy en día la emergencia de la universidad por aquellos siglos.

Este proceso, antesala de la reforma que dará lugar al sistema universitario, va acompañado o precedido por la aparición cada vez mayor de detractores, corruptores y depredadores del paradigma en vigencia hasta ese momento: las escuelas, los maestros y los discípulos, y la formación en las artes liberales, empiezan a ser atacadas, despreciadas, corrompidas, subvertidas y desprestigiadas de todas las maneras posibles, por diversos agentes sociales o figuras que encarnan esta suerte de «oleada» de adversarios, satirizadotes, reformistas, críticos y agresores de toda índole. Por si fuera poco, se incrementan las dificultades económicas para poder rentar habitación o alojamiento y poder estudiar.

Hay algún parecido, inclusive, con otros fenómenos históricos como la aparición, nociva por cierto y deletérea, de los escépticos en la Antigüedad tardía — Sexto Empírico y compañía, por poner un ejemplo- acompañado de la proliferación de los cínicos en su versión más decadente, destructiva y degenerante, o el escepticismo irracionalista del siglo XVI o XVII que obliga a que aparezca un Descartes a escribir las Meditationes, o el relativismo anti-humanista y posmoderno, enemigo confeso de cualquier forma de racionalidad.

No sabemos hasta qué punto estos movimientos u «oleadas» fueron dirigidos desde las sombras o alentados desde algún sector, pero, como quiera que sea, son fenómenos que suelen repetirse a lo largo de la historia de civilización, de la cultura o de la filosofía. Y éste es el clima en el que ya late y hace sentirse la presencia y el advenimiento del Cornificio.

El Cornificio es una figura antigua, y atemporal, que encarna y personifica al cinismo más grotesco y desvergonzado, que pondera hipócritamente un purismo o sinceramiento en nombre de los cuales se atacan y se condenan como superficiales, sobrantes e innecesarias a todas aquellas cosas que ennoblecen y embellecen nuestras vidas como personas, como sociedad y como civilización. Con el más repugnante descaro, el Cornificio se exalta en su presunta sinceridad con la que pretende estar autorizado para ejercer su desparpajo y su insolencia, e invoca un minimalismo purista, o esencialista, para justificar su espíritu depredador que cuestiona y desprecia a la hermosura de las 
formas, a la elegancia en el hablar, a la abundancia artística y creativa, a todo lo grande y lo sublime en nuestras obras y en nuestros actos, al trato profundo, demorado y delicado de las palabras. El Cornificio es la subversión de todos los criterios; es cínico, hipócrita y relativista; confunde honestidad con sinceridad; confunde amor excluyente a lo esencial con insensibilidad estética; detesta y condena como inútil todo aquello que no ofrece una aplicación práctica visible, inmediata o redituable.

El Cornificio también es el perfecto «hombre-vientre», como decían los antiguos, pero que se nos puede presentar como filósofo o político o artista o crítico de arte, incluso con licencias y cargos honrosos, acaso laureado y con renombre y con título de docto, pero que en verdad no es más que un asno desprovisto de toda sensibilidad hacia la belleza, hacia la justicia, hacia lo bueno, hacia lo excelso y hacia lo luminoso. Es pedante y no tiene tolerancia por nada; es el petulante y soberbio que califica de petulantes y soberbios a quienes objetan sus decisiones o su autoridad o no lo reverencian; odia, febril y envenenadamente, a quienes delatan que el rey va desnudo, que consiste en una farsa, una mentira, y que no es más que fama, o que títulos académicos, rótulos y etiquetas, o altos cargos, o aprobación del público, pero en el fondo nada más que eso; se arroga ser el juez universal de lo útil y de lo inútil, de lo que se debe rescatar y conservar y de lo que se debe descartar y poner en venta; es el desamortizador voraz, obsesivo, insaciable, de todo lo enaltecedor, ennoblecedor, precioso y brillante; puede creerse con derecho a ridiculizar, destruir o criticar a la tradición, a tirar por la basura todo aquello que no pueda comprender o que es incapaz de encontrarle significado, o desechar todo lo que le parezca anacrónico o «improductivo».

Como una especie de Anticristo de la cultura, de la tradición, de la civilización, el Cornificio, cínico, reduccionista e iconoclasta, arremete contra la elocuencia, contra las metáforas, contra las figuras retóricas, contra las imágenes, contra todo buen gusto y sentimiento estético, contra las costumbres de los antiguos, contra las técnicas en el aprendizaje, contra los principios artísticos, poéticos e inspirados, ya que frecuentemente aduce que estos dones, además de ser tranquilamente prescindibles, son dados por gracia de la naturaleza (Metalogicon, I, 8).

El Cornificio tiene múltiples manifestaciones; Juan de Salisbury describe en el Metalogicon una tendencia específica que advierte en su época; habla de tendencias innovadoras, reformismo, de nuevos métodos, de desprecio por la elegancia y por la retórica («superflua sunt preacepta eloquentiae») (Metalogicon, I, 7); describe sujetos que carecen de sensibilidad frente a lo horripilante, frente a la fealdad, frente a lo sórdido, frente a lo estúpido, frente a lo absurdo y sinsentido; son descarados y arrogantes, sólo resguardan y respetan lo redituable en títulos, en dinero o en honores y reconocimientos; bajo el reinado del Cornificio, la belleza, la elocuencia, la distinción, la perfección, la hermosura, el esplendor, la excelsitud, el refinamiento... serán lujos de los que se puede prescindir, esencialmente innecesarios para nuestras vidas, para nuestros edificios, para nuestros parques, para nuestros hábitos de vestir, para nuestra manera de hablar y de escribir, en fin: accesorios caros y excepcionales reducidos al ámbito de los museos o de las exposiciones de arte - si con suerte encontramos algo, de lo mucho que se sigue rotulando como «arte» y exhibiéndose como tal, que pueda en muchos casos ser digno de ese nombre. 
La embestida triunfal del Cornificio contrae un rasgo decisivo, que es la separación definitiva entre la cosa (res) y las palabras (verba), que atravesará determinante toda la tradición filosófica occidental, expresado en una de las sentencias cornificianas más trágicas y contundentes del Metalogicon: «Res enim philosophia, aut finis eius quae est sapientia quaerit non verba» («La filosofía, que tiene por fin la sabiduría, la cosa investiga, y no las palabras») (Metalogicon, I, 6). En esta sentencia queda signado y consumado el divorcio entre Filología y Mercurio.

Sobre esta configuración de tendencias y circunstancias nace la universidad. Con las universidades tiene lugar la unificación de la enseñanza, a partir de ahora institucional y uniforme, regida por normativas y estatutos aprobados por las máximas autoridades eclesiásticas; se instituye la enseñanza asalariada, lo cual puede ser visto como un progreso, o como la transformación del maestro en el empleado de una institución; la relación entre maestro y discípulos es anegada por todo un cuerpo de reglamentaciones fundado por la estructura institucional y normativa, al mismo tiempo que se instaura el sistema de los exámenes, que constituyen una institución-pilar dentro de la institución mayor que es la universidad. La educación, la formación, pasa de tener la estructura de una sociedad iniciática pitagórica o académica en sentido griego, o como en la que se forma un brahmán o un rabino, a tener la impersonalizada estructura de una institución estatal o religioso-estatal.

Nos preguntamos en qué medida la universidad, en tanto triunfo de un proyecto institucionalizador, no es un triunfo del Cornificio. De ninguna manera queremos decir con esto que el Cornificio sea equivalente a la universidad o que haya sido personificado por la universidad. Por otro lado, en modo alguno pretendemos desconocer la grandeza de la universidad como institución formativa de la civilización occidental; simplemente realizamos esta pregunta desde dos perspectivas: desde lo que se perdió, se desechó y se excluyó de la tradición educativa anterior, y luego desde las fallas, fracasos y falencias que tiene este sistema en la actualidad, que es el mismo que se aplicó también y rige en la educación primaria y secundaria, no tan sólo en la superior, que en muchos casos se ha convertido en una maquinaria de empleados, becarios y clientes, de diplomas y diplomados que en muchos países se obtienen en una carrera maratónica angustiosa, febril, apresurada, sin placer, sin espíritu, sin hondura, insensiblemente... sin amor. Más allá de la figura del Cornificio, nos preguntamos, más bien, en qué medida los problemas de este sistema no tienen consecuencias que repercuten en todos los órdenes de la vida humana, de la sociedad, de la cultura y de la civilización actual, ya que en ella se forman los médicos, los políticos, los arquitectos, los profesores, los pedagogos, los juristas, los científicos, los psicólogos, los economistas, y muchos filósofos y escritores y artistas han pasado por ella o reciben influencia. Y en qué medida no debemos rastrear los principales defectos del sistema hoy vigente en sus orígenes medievales, donde se rompe para siempre la relación íntima y determinante maestro-discípulo y se la sustituye por una relación mediada entre docentes-institución-estudiantado, y se instauran los oprobiosos sistemas de exámenes, tan criticados por sabios de nuestro tiempo como Borges o Mario Bunge, que nacen con la universidad medieval, y que - como observa el filósofo y epistemólogo argentino- han fomentado el estudio de memoria, o sea el estudio sufrido, tenso, estresado, mediocre, agobiante, superficial, y no basado en el aprendizaje, sino el aprendizaje constituido y conformado por y para el examen. 
Nuestra hipótesis es que, más allá de las críticas y los elogios, los defectos y las virtudes, de este nuevo sistema que se instaura más o menos hacia el siglo XII en Europa, el hecho cierto, objetivo, innegable y constatable por cualquiera, es que con la universidad vence y triunfa la Teología. No lo decimos por el hecho de que, gracias al sistema universitario, las órdenes monásticas empiezan a apoderarse progresivamente de la educación, sino porque las artes liberales son desplazadas, pasan a un plano de inferioridad, y son — como ya hemos dicho y repetido— desposeídas y despojadas, y quedan bajo subordinación y servidumbre de la Teología (Ferruolo 1985), la gran soberana a partir de aquel momento. Y es paradójicamente en este período, bajo el reinado de la Teología, donde prevalece el racionalismo, ya advertido con alarma y con pavor por Juan de Salisbury, un racionalismo que luego alcanzará la saturación con la grandiosa y sofisticada pero gélida y deslucida escolástica; un racionalismo que acaso se utilizó como arma para socavar y debilitar a las artes y al espíritu de las escuelas; un racionalismo que evoca resabios del que ya había sido usado siglos atrás por los Padres de la Iglesia para despreciar y agredir a las creencias y religiones de los demás; un racionalismo, en fin, chato, iconoclasta, mediocrizante, y en última instancia, depredador y empobrecedor.

\section{La acedia, el pecado olvidado y sucesivamente tergiversado}

La acedia es uno de los pecados que hoy en día se conoce como «pereza». Anteriormente se había conocido, durante mucho tiempo, como «tristeza» (tristitia), o según Tomás de Aquino, más específicamente «tristeza por el bien de Dios». El concepto también ha circulado como «flojedad», «indolencia»o «aburrimiento». Parecería que los pecados se van adaptando conceptualmente a lo que exigen los vientos históricos, el clima social de cada época y de cada sociedad; mientras que una época en la que prevalecía una perspectiva religiosa sobre la vida la acedia era concebida como un estado de vacío de alegría ante la Creación, o bien, ante los bienes divinos que nos aguardan, en una sociedad que revaloriza excesivamente el trabajo y la productividad la acedia es interpretada como pereza. Algo parecido ocurrió con la plegaria del Padre Nuestro, en el que se ha cambiando en las últimas décadas la palabra «deudas» («perdona nuestra deudas») por «ofensas» («perdona nuestras ofensas»). Por otra parte, algunos Padres del Desierto se han referido a este pecado como un vacío existencial, como la experiencia del sinsentido ante la vida. Me atrevería a decir que aquellos antiguos anacoretas cristianos llamaban acedia a lo que nosotros llamaríamos nibilismo: ser posesos por una visión y un sentimiento nihilista respecto al mundo, al porvenir y a la misma existencia (Conejo Feliu).

No obstante, ninguno de ellos parece ser el significado exacto, original y cabal de este concepto. Parece más bien estar asociado a la pesadez, al embotamiento, a la indiferencia, al letargo, a la insensibilidad. Creemos, en efecto, que el término insensibilidad nos brinda la mejor aproximación conceptual a lo que verdaderamente es la acedia. La palabra original es $\square \kappa \eta \delta \propto$, y significa dejadez, descuido, indiferencia, negligencia, desidia. No es lo mismo que decir «tristeza», ya que hay muchas 
personas con estas características que sin embargo mantienen un sentido del humor o un estado anímico bastante estable y alejado de la tristeza. Tampoco es lo mismo que decir nibilismo o que sentir un vacío existencial, ya que hay muchas personas con esos rasgos en su forma de ser y de vivir que, a pesar de eso, no manifiestan ni experimentan ninguna «crisis de sentido» en sus vidas; en el mundo abundan personas indolentes, desidiosas, descuidadas, que no sufren depresiones ni angustias profundas ni se apodera de ellos una visión de la vida como si todo fuera un gran absurdo. Nos parece entonces que el significado originario de este término no es en manera alguna el que fue adquiriendo después; en un principio fueron variaciones, leves alejamientos del significado original, pero pronto el sentido preciso y profundo de este concepto se perdió por completo. ¿Será fortuito que esto haya sucedido? ¿no hay en este hecho algo verdaderamente significativo? ¿hubo subversiones conceptuales deliberadas de este término?

La acedia es insensibilidad, indiferencia y desidia. Esto se aplica a todos los órdenes de la vida humana. Es éste el significado de este pecado capital, y no otro. La acedia es la insensibilidad ante lo antiestético, ante las injusticias, ante el hacinamiento, la promiscuidad y la falta de espacios, ante los abusos de toda índole, ante la insalubridad y la contaminación, ante la crueldad, ante la suciedad, ante los excrementos, publicidades y ruidos que invaden nuestras calles y nuestros parques, ante la estupidez, ante la indigencia en todas las formas en que se pueda presentar. La acedia es el mal gusto de los arquitectos y de los nuevos artistas; es la mediocridad de nuestro de sistema de gobierno que creemos que es el mejor se ha inventado hasta nuestros días; es la tecnocracia y el productivismo, el reduccionismo de todo a lo productivo y a lo útil; es la pérdida de toda relación con lo divino y de todo sentido de lo sagrado.

Acaso la acedia sea el pecado más vigente y expandido en nuestra época, desde los últimos siglos, y en la actualidad particularmente. ¿Acaso no nos encontramos en la medianoche de una Edad Oscura? ¿Nos hemos vuelto de tal forma insensibles a las Artes que nos resultan incomprensibles, irreconocibles y extrañas? ¿Es esto acaso evidencia del imperio cornificiano y del destierro de las Musas?

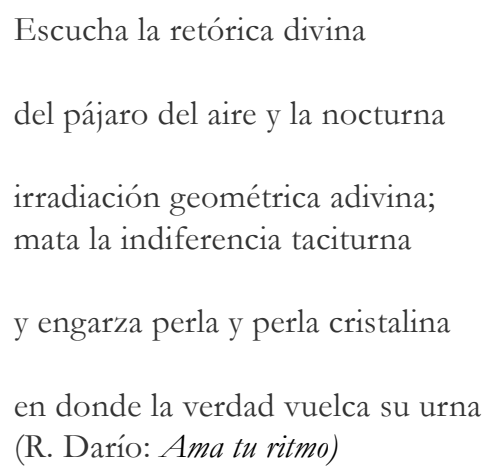


Diego Pintado. El reinado del Cornificio y el exilio de las Musas. El filósofo educado en las Artes en la Antigüedad arcaica y en la Europa medieval hasta el siglo XII

\section{Conclusiones}

En este estudio, breve para la complejidad y vastedad del tema en cuestión, hemos intentado describir la historia de una tradición educativa y formativa que estuvo vigente en Occidente durante largos siglos, acaso desde tiempos arcaicos, y fue sustituida por un nuevo paradigma hacia el siglo XII, el modelo universitario, que es el modelo institucional.

A modo de conclusión, trazamos estas observaciones generales:

— durante siglos, los antiguos y los medievales, fueron educados y formados en conformidad con las Musas, y posteriormente con las Artes

- el modelo formativo-educativo de las Artes liberales ponderó en la tradición occidental a través de escuelas, constituidas entorno al maestro

- ese modelo formativo-educativo, que precede a la universidad, no es institucional y su característica fundamental es que está centralizado en el maestro, y no en la institución ni en los estatutos ni en normativas institucionales

- hacia el siglo XII, aproximadamente, surge la tendencia, impulsada por el clero fundamentalmente, de institucionalizar la educación y la formación, y así se da origen a la universidad

- la universidad instaura un régimen institucional para regular las acreditaciones y habilitaciones, las licencias para enseñar o para ejercer la profesión, y al mismo abandona el paradigma educativo basado en una relación directa entre el maestro y el discípulo y lo sustituye por un paradigma centralizado en la institución, en las reglas y normativas institucionales

Ya hemos anticipado anteriormente algunas de las consecuencias que ha tenido la instauración del sistema universitario en la cultura occidental, y nos hemos preguntado si acaso no debemos lamentar esa ruptura y abandono definitivo de aquella tradición en la que la relación discípulomaestro era nuclear, indisociable, esencial y fundamental.

La institucionalización de la educación fue originada, según los historiadores, a raíz de una crisis dada por un problema entorno al criterio para otorgar licencias y habilitaciones profesionales. El criterio que prevaleció hasta entonces se puso en crisis, fue cuestionado: se consideró que el criterio per se del maestro para facultar no era suficiente. Se creó para ello la institución, con sus normativas y reglamentaciones. Inevitablemente, la institucionalización de la educación obligó —no pudo ni podrá ser de otra manera- a centralizar la labor formativa y educativa en los exámenes: el examen se convirtió, hasta hoy, en el epicentro de la educación. Se abandonó el modelo que lo confiaba todo en el presunto buen juicio del maestro y se lo sustituyó por un modelo que lo confía todo en la presunta eficacia de los exámenes. La pregunta más pertinente pareciera ser ésta: cómo salir de un sistema de formación centrado en el examen; cómo hacer para concebir un nuevo paradigma 
educativo sin los exámenes; cómo concebir un sistema en el que el mismo maestro esté examinando a cada momento y no tenga necesidad de imponer uno o dos o más exámenes durante el curso ni el estudiante esté forzado ni condicionado ni pendiente del examen como el objetivo último y a la vez inmediato de toda su formación, lo cual nos induciría a tomar en consideración —seriamente y no sin alguna urgencia - la posibilidad de revalorizar y rescatar elementos propios de aquella tradición arcaica y luego clásica que precedió al paradigma educativo institucional, en vigencia hasta hoy a partir del nacimiento de la universidad.

\section{Bibliografía}

Capela, M. (2016) Las nupcias de Filologíay Mercurio, vol. I, Madrid, Consejo Superior de Investigaciones Científicas

Conejo Feliu, I. «La acedia, rasgo de la sociedad actual», Facultad de Humanidades, Universitat Pompeu Fabra [en línea: https://repositori.upf.edu/bitstream/handle/10230/25286/ Conejo_2015.pdf?sequence $=1$;

21/09/2016]

Disandro, C. (1995) El reino de la palabra: semántica y transfiguración, La Plata, Fundación Decus

—. (2004) Humanismo: fuentes y desarrollo histórico, La Plata, Fundación Decus

Ferruolo, S. (1985) The rigins of the Universities: The Schools of Paris and Their Critics, 1100-1215, Stanford, Stanford U Press

Higuera Rubio, J. (2013), «Las artes del Arte: las artes liberales en la evolución del Arte luliano», Medievalia, Nro 16, p. 71-79.

Liberá, A. de (2000) Pensar en la edad media, Barcelona, Anthropos.

Shanzer, D. (1986) A Philosophical and Literary Commentary on Martianus Capella's De Nuptiis Philologiae et Mercurii. Book 1, California, U California Press

Tamayo y Salmorán, R. (1987) La Universidad, epopeya medieval, México, UNAM. 